EPJ Web of Conferences 32, 04021 (2012)

DOI: $10.1051 /$ epjconf/20123204021

(C) Owned by the authors, published by EDP Sciences, 2012

\title{
Test bench for ITER gyrotrons. Measurements of the RF power value during tests of the ITER-prototype gyrotrons
}

\author{
A.P. Khvostenko ${ }^{1}$, G.G.Denisov², V.I.Ilin ${ }^{1}$, P.P.Khvostenko ${ }^{1}$, V.A.Kochin ${ }^{1}$, V.I.Malygin ${ }^{2}$, \\ V.E.Myasnikov ${ }^{3}$, L.G.Popov ${ }^{3}$, E.A.Soluyanova ${ }^{3}$, E.M.Tai ${ }^{3}$, and S.V.Usachev ${ }^{3}$ \\ ${ }^{1}$ Institute of Tokamak Physics, NRC "Kurchatov Institute", Moscow, RF \\ ${ }^{2}$ Institute of Applied Physics, RAS, N. Novgorod, RF \\ ${ }^{3}$ GYCOM Ltd., N. Novgorod, RF
}

\section{Introduction}

An increase of the industrial production and population in the world requires search and introduction of the new energy sources. Controlled thermonuclear fusion is one of the most promising sources of obtaining energy. At present, the international experimental thermonuclear reactor ITER is built in France (Cadarache). For additional plasma heating in ITER twenty four gyrotrons generating RFpower at the $170 \mathrm{GHz}$ frequency will be used. Russian Federation within the framework of ITER obligations, must supply eight gyrotrons [1]. Before delivery, the gyrotrons must be tested on the test bench, which was built in Institute of tokamak physics, NRC "Kurchatov Institute".

Test bench for the work in the continuous $(\mathrm{CW})$ regime is equipped with the high-voltage power supplies, water cooling and vacuum pumping systems, evacuated transmission line, which connects gyrotron with the terminal load, the protection and blocking system, technological diagnostics, the systems of the experimental data acquisition, processing and archiving.

\section{Technological systems of the test bench}

\subsection{High-voltage power supply system}

High-voltage power supply system includes basic and supplementary sources.

Basic source has following parameters: cathode voltage $U_{c} \leq-80 \mathrm{kV}$, cathode current $\mathrm{I}_{\text {cath }} \leq 50 \mathrm{~A}$; pulse duration $-\mathrm{CW}$.

Parameters of the supplementary source are: gyrotron body voltage $-\mathrm{U}_{\mathrm{rec}} \leq+45 \mathrm{kV}$; body current $-\mathrm{I}_{\text {rec }} \leq 1.0 \mathrm{~A}$; pulse duration $-\mathrm{CW}$.

\subsection{Evacuated transmission line and high vacuum pumping (HVP) system}

The transport of RF power through the transmission line in the frequency range of 120-170 GHz can be realized by the different methods: with the atmospheric pressure in the transmission line, with the filling of transmission line by SF6 gas and at pressure inside transmission line above normal atmosphere. But safest method of the RF power transfer is the transport through the evacuated transmission line. The advantage of this method consists in the practical absence of electrical breakdowns in the transmission line at the pressure $\mathrm{p}<$ of $10^{-2} \mathrm{~Pa}$, in the mechanical loads reduction on the output diamond window. 
The transfer of RF power from the gyrotron (Fig. 1) through the diamond window, the matching optics unit (MOU) to the terminal load is produced through the transmission line by the length of $\sim 10 \mathrm{~m}$, which contains waveguides with the diameter of $89 \mathrm{~mm}$ (Fig. 2). HVP provides the obtaining of operating pressure in the transmission line in the range $\mathrm{p}=10^{-3}-10^{-5} \mathrm{~Pa}$. The total pumped out volume is equaled $\sim 0.5 \mathrm{~m}^{3}$. The schematic vacuum diagram of test bench is shown in Fig. 3 [2].

HVP system includes: the rough down pumping system, high vacuum pumping system, control system. The rough down pumping system is assembled on the base of the mechanical pump (NL1) by productivity of $16 \mathrm{l} / \mathrm{s}$. This pump provides evacuation of working volume from the normal atmospheric pressure down to a pressure of $\mathrm{p}<10 \mathrm{~Pa}$. High vacuum is ensured by the high vacuum cells, assembled on the base of turbo molecular pump (NR) by productivity $200 \mathrm{l} / \mathrm{s}$ and of turbo molecular aggregate of Pfeiffer firm, by productivity of $210 \mathrm{l} / \mathrm{s}$. The composition of residual gas in the transmission line is controlled by the mass spectrometer MX 7304A (S), including for the analysis of residual gases during the of RF power transport. Operating pressure in the camera of the mass spectrometer $\mathrm{p}<10^{-3} \mathrm{~Pa}$.

For averting the entry of RF (wavelength $\sim 2 \mathrm{~mm}$ ) power into vacuum system during gyrotron operation, pumping system is connected to the transmission line through the copper membrane with a thickness of $2 \mathrm{~mm}$, with a diameter of $100 \mathrm{~mm}$, supplied with 5600 holes with a diameter of 0.8 $\mathrm{mm}$. Control of vacuum equipment operation is produced by means of the computer.

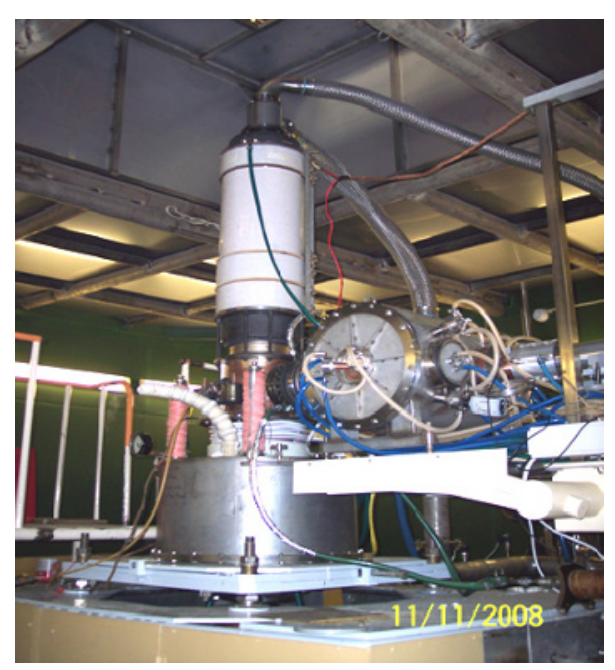

Figure 1. Gyrotron in the test bench

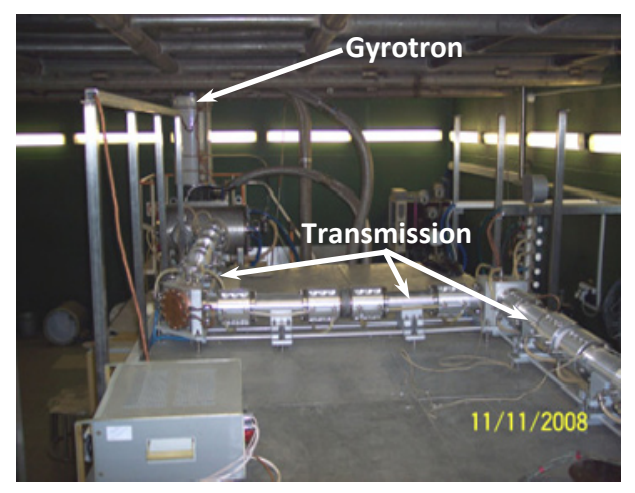

Figure 2. Transmission line

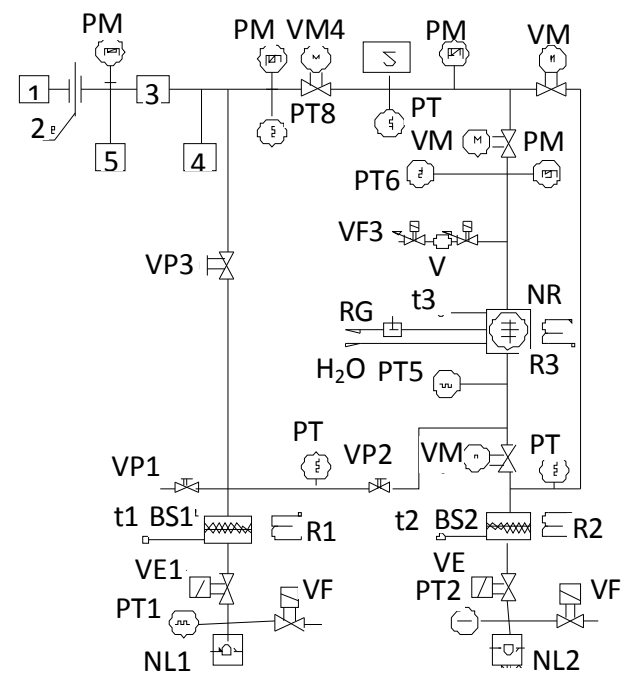

Fig.3. Schematic vacuum diagram of test bench: 1 -gyrotron; 2 - diamond window; 3 transmission line; 4 - SHF-load; 5 - turbo molecular aggregate of Pfeiffer firm; NL1, NL2 mechanical pumps; NR - turbo molecular pump (TMH-01-400 AB); PT1 — PT8 - rough vacuum sensors of the type ПMT-6-3; VF1, VF2 - normally opened, VF3, VF4 - normally closed emergencyblending in electromagnetic valves; VE1, VE2 emergency electromagnetic valves; BS1, BS2 sorption traps (filters); VP1-VP3, VP4- handoperated valves; VM1-VM4 - regulated electromechanical valves; PM1-PM4 - high vacuum sensors of the type ПММ-32-1; S - mass spectrometer MX-7304A; R1, R2 - heaters for traps BS1 and BS2, respectively; R3 - heater for turbo molecular pump; $\mathrm{t} 1, \mathrm{t} 2$ - thermocouples for traps $\mathrm{BS} 1$ and, BS2 respectively; $\mathrm{t} 3$ - thermocouple for turbo molecular pump TMH-01-400 AB 


\subsection{Water cooling system}

Water cooling system provides a heat removal from the elements of gyrotron construction and transmission line with the terminal load. The basic objects of cooling are: collector gyrotron (water mass flow rate $\mathrm{Q} \leq 25 \mathrm{~kg} / \mathrm{s})$; resonator $(\mathrm{Q} \leq 1.5 \mathrm{~kg} / \mathrm{s})$; terminal load $(\mathrm{Q} \leq 15 \mathrm{~kg} / \mathrm{s})$; elements of transmission line construction $(\mathrm{Q} \leq 2 \mathrm{~kg} / \mathrm{s})$.

In the system of the water cooling of the test bench elements the following parameters are recorded: temperature, pressure, mass flow rate, and also the presence/the absence of water in the mains of cooling.

Sensors are completed by the devices, which can form at the output: the analog, digital (protocol RS-232), and also relay (discrete) signals, which are used in control system of test bench equipment. All sensors (analog, digital and discrete channels) are connected to the data acquisition system.

In addition, the special device, using the sensor signals, forms commands into the system of protection and blockings.

For illustration, the arrangement of the temperature sensor, water mass flow rate sensors and pressure sensors on the water mains are shown in Figs.4, 5.

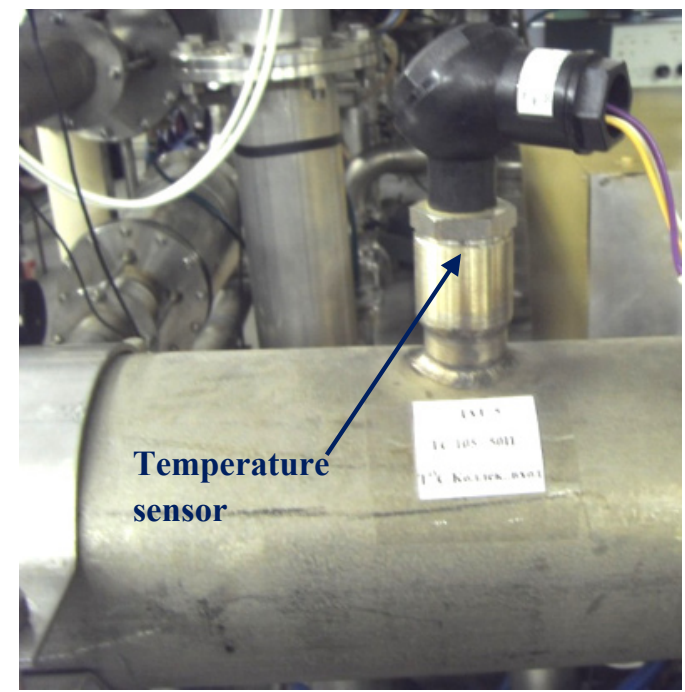

Figure 4. Arrangement of temperature sensor on the water main of collector cooling

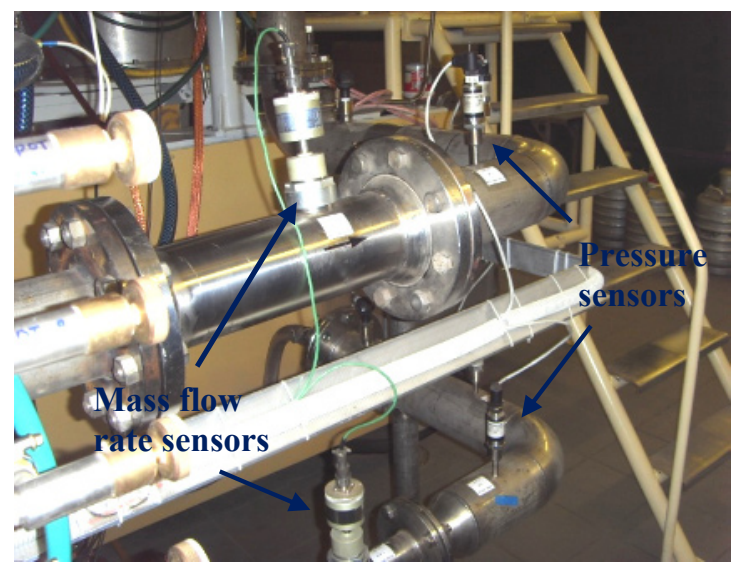

Figure 5. Arrangement of mass flow rate sensors and pressure sensors

\subsection{System of the experimental data acquisition, processing and archiving}

Control of vacuum equipment and data acquisition is produced with the aid of the personal computer with the I/O board LA - 48 (control, 48 channels), the ADC board L -card 783 ( 32 channels) and the instruments of the data acquisition of the analog sensors of rough and high vacuum, water temperature and mass flow rate.

The program of control and data acquisition is realized by two windows on computer monitor: by the screen of control and the screen of data acquisition.

Vacuum schematic diagram with the designation of elements and panel of graphs are placed on the screen of control (Fig. 6). On the panel of graphs it is simultaneously represented fourteen cells for the visualization of the graphs of the technological parameters in the regime of on-line. 


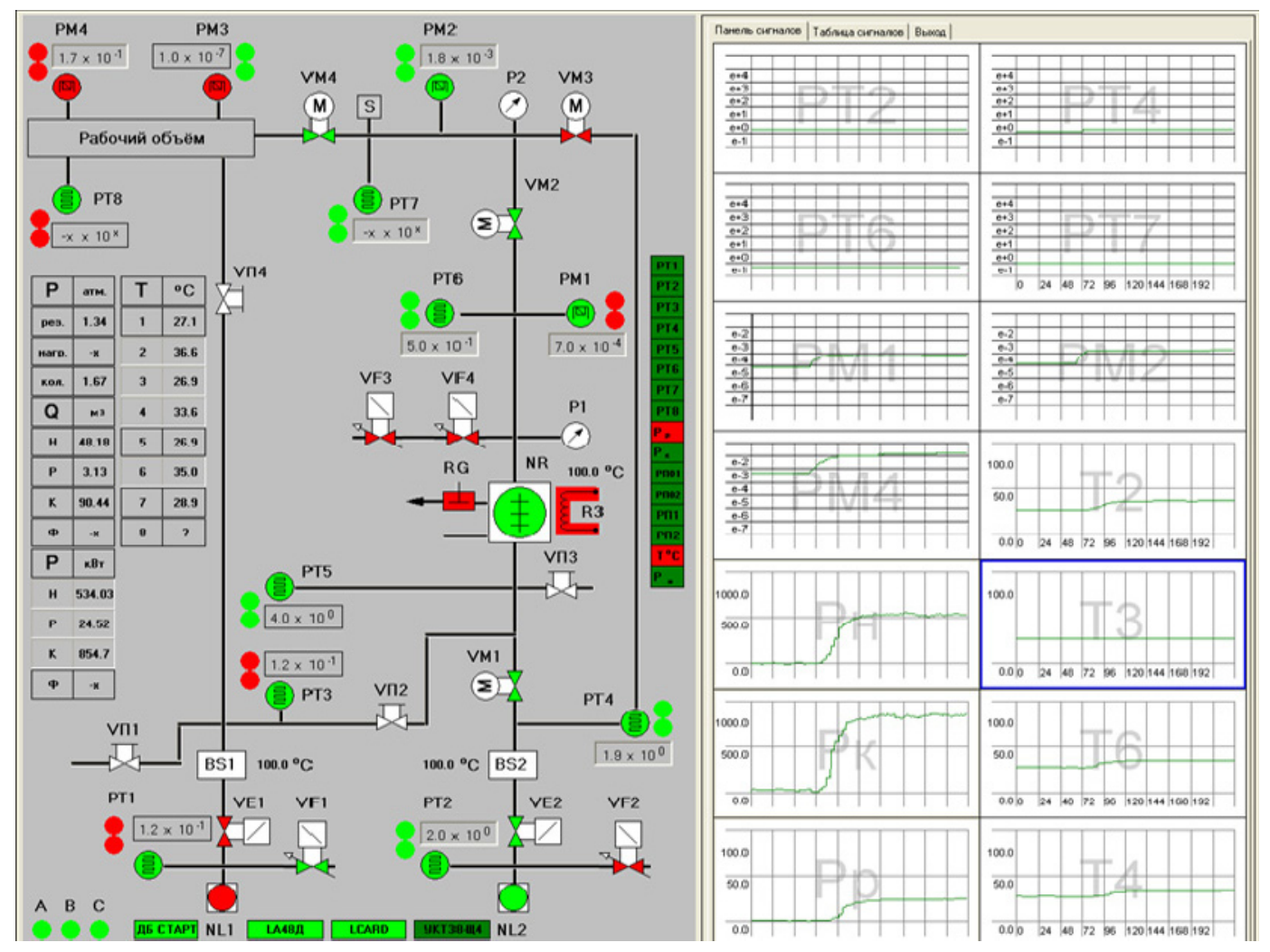

Figure 6. Screen of HVP system control

\subsection{Gyrotron protection and blockings system}

The protection and blockings system has several steps. In the case when time derivative of cathode current $\mathrm{I}_{\mathrm{c}}$ rich the value $+10^{6} \mathrm{~A} / \mathrm{s}$, crowbar system is activated (crowbar triggering time less than 10 $\mu \mathrm{s})$. Released energy inside the waveguide is not more than $\approx 10 \mathrm{~J}$.

For RF arc protection system the light detectors are used. Light detectors were mounted close to CVD window, MOU, relief load and terminal load. Light detectors signals activate crowbar system when the level of light signal becomes more than the threshold value.

Regimes of gyrotron cut off or of normal RF power generation are determined by the level of the RF diode signal. RF diode is installed on the micro band of the transmission line gyrotron - the terminal load. Cut off system is activated crowbar system in $30 \mathrm{~ms}$ after high voltage turning on, if during this period a signal from the detector did not appear. During the waveguides conditioning the regimes with cut off or normal generation are possible. In this case when the total time of cut off regime become equal to $100 \mathrm{~ms}$ the crowbar system will be activated also.

\section{Measurements of thermal loads on the elements of gyrotron and terminal load by the calorimetric method}

One of the tasks during gyrotrons tests is the determination of the generated power level, and also of the thermal loads on the elements of the gyrotron. Thermal power absorbed in the collector, resonator and in the terminal load are determined by calorimetric method. Average heat load was calculated by the formula:

$$
P=c \cdot m \cdot\left(T_{\text {out }}-T_{\text {in }}\right)(W)
$$




\section{EC-17 Workshop}

where $\mathrm{c}$ - water heat capacity $\sim 4200 \mathrm{~J} / \mathrm{kg} \cdot \mathrm{grad}, \mathrm{m}$ - water mass flow rate $\mathrm{kg} / \mathrm{s}(1 / \mathrm{s}), \mathrm{T}_{\text {in }}$ и $\mathrm{T}_{\text {out }}-$ inlet and outlet temperatures of water, ${ }^{\circ} \mathrm{C}$.

The calculated amounts of heat loads in the regime of real time were derived on the screen of monitor and archived. For illustration the temporal behavior of the average heat powers, absorbed in the collector, resonator and terminal load, calculated according to formula (1), and also of average total heat power during the gyrotron Vesuvius-9 tests is given in Fig. 7. An error of measurement of heat loads comprised not more than $3-5 \%$.

The measured values of total heat power were compared with the total electrical power $\mathrm{P}_{\mathrm{el}}$, calculated by formula (2):

$$
P_{e l}=U_{c} \cdot I_{c}+U_{r e c} \cdot I_{r e c}(W)
$$

where $U_{c}$ and $I_{c}$ - voltage and current of basic source, $U_{\text {rec }}$ and и $I_{\text {rec }}$ - voltage and current of supplementary source. Voltages and currents of the basic and supplementary sources during the tests in the pulses by duration up to $1000 \mathrm{~s}$ were measured and processed by the program WinScope. An example of $1000 \mathrm{~s}$ pulse registration with the output power of $0.85 \mathrm{MW}$ during the gyrotron Vesuvius -11 tests is shown in Fig. 8.

The measured values of total thermal power were coordinated with the total electrical power with the accuracy not of worse than $5 \%$.

\section{Results of the tests of gyrotrons Vesuvius $-9,10,11$}

From the autumn of 2008 until December 2011 the tests of the prototypes of ITER gyrotron - of the gyrotrons Vesuvius- 9,10,11 were carried out. The temporal behavior of the average heat powers, absorbed in the collector, resonator and terminal load and of average total heat power during the tests of gyrotrons Vesuvius-10 and Vesuvius-11 is presented in Figs. 9, 10.

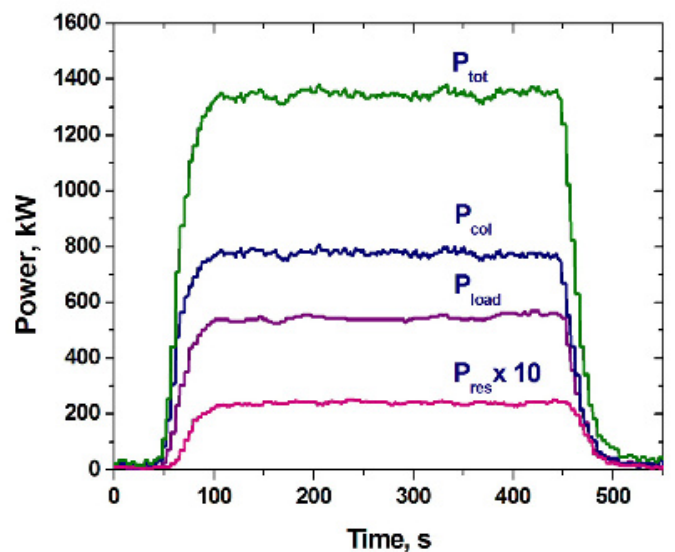

Figure 7. Temporal behavior of the average heat powers, absorbed in the collector, resonator and terminal load, and also of average total heat power during the gyrotron Vesuvius-9 tests

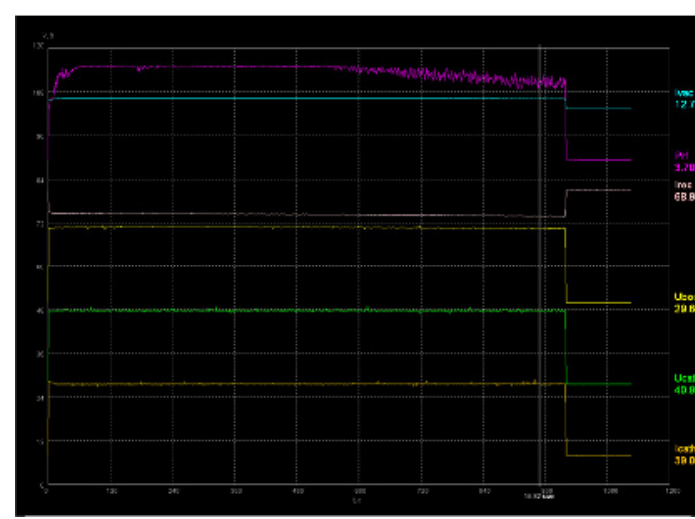

Figure 8 . The time characteristics of voltages and currents of basic (Uc, Ic) and supplementary (Urec, Irec) sources during the gyrotron Vesuvius-11 tests

Pressure in the transmission line during pulse transport by the duration several of hundred seconds changed weakly and composed $\mathrm{P} \sim 3-510^{-4} \mathrm{~Pa}$. The temporary behavior of the pressure value for the pulse with the power $750 \mathrm{~kW}, 1000 \mathrm{~s}$ during the tests of gyrotron Vesuvius -10 are presented in Fig. 11.

The test results of the gyrotrons Vesuvius $-9,10,11$ are brought to Table 1 [3]. 


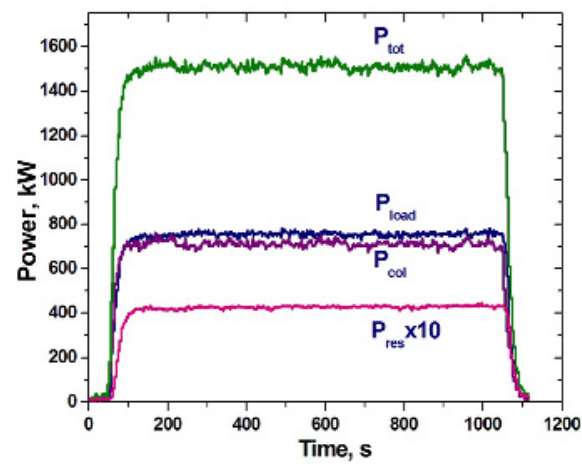

Figure 9. Temporal behavior of the average heat powers, absorbed in the collector, resonator and terminal load $(\sim 750 \mathrm{~kW})$ and of average total heat power during the gyrotron Vesuvius -10 tests

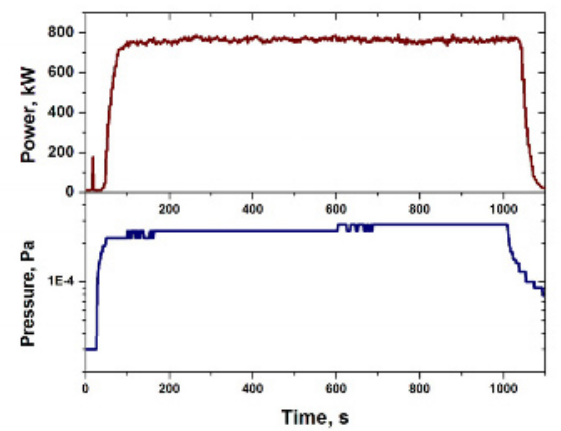

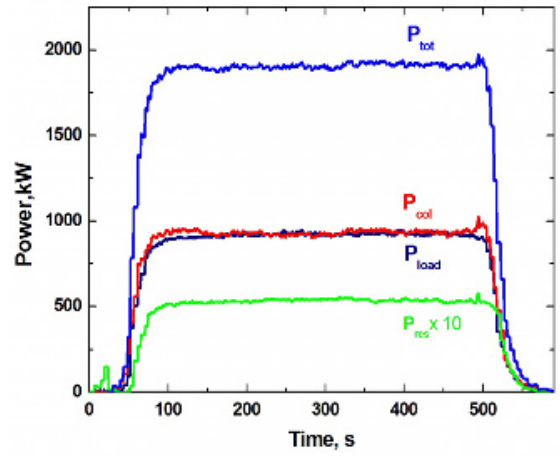

Figure10. Temporal behavior of the average heat powers, absorbed in the collector, resonator and terminal load $(\sim 960 \mathrm{~kW})$ and of average total heat power during the gyrotron Vesuvius -11 tests

Table 1.

\begin{tabular}{|c|c|c|c|}
\hline Gyrotron & $\begin{array}{c}\text { Power at } \\
\text { MOU } \\
\text { outlet, } \\
\mathrm{kW}\end{array}$ & $\begin{array}{c}\text { Effici- } \\
\text { ency, } \\
\%\end{array}$ & $\begin{array}{c}\text { Pulse } \\
\text { duration, s }\end{array}$ \\
\hline Vesuvius -9 & 550 & 40 & 800 \\
\hline Vesuvius -10 & 750 & 54 & 1000 \\
& 960 & 53 & 600 \\
\hline Vesuvius -11 & 850 & 53 & 1000 \\
& 960 & 55 & 400 \\
& 1300 & 50 & 100 \\
\hline
\end{tabular}

Figure 11. Temporal behavior of the pressure value inside transmission line

\section{Conclusion}

1. The test bench for gyrotron testing, built in the Institute of tokamak physics, NRC "Kurchatov Institute", has demonstrated the reliable operation of its systems in the process of the tests of ITER prototypes gyrotrons: Vesuvius $-9,10,11$.

2. The results of the tests of gyrotrons Vesuvius $-9,10,11$ have shown the possibility of the reliable transport of RF power up to $1.3 \mathrm{MW}$ from the gyrotron to the terminal load through the evacuated transmission line.

\section{References}

1. A.G. Litvak, G.G. Denisov, V.E. Myasnikov, E.M. Tai, E.A. Azizov, V.I. Ilin, Proceedings of 23rd IAEA Fusion Energy Conf., 11-16 October, Daejon, Korea, (2010).

2. V.I. Ilin, A.V. Konovalov, V.A. Kochin, V.A. Mikhailichenko, A.P. Khvostenko, Problems of atomic science and engineering, Series Thermonuclear fusion, Issue 2, pp. 58-64, (2011).

3. S.V. Usachev, L.G. Popov, V.I. Ilin, M.V. Agapova, G.G. Denisov, A.Ph. Gnedenkov, V.N. Ilin, A.P. Khvostenko, A.N. Kostyna, A.N. Kuftin, A.G. Litvak, V.I. Malygin, V.E. Myasnikov, V.O. Nichiporenko, V.N. Novikov, V.G. Rukavishnikova, E.V. Sokolov, E.A. Soluyanova, E.M. Tai, V.G. Usov, Yu.M. Yashnon, V.E. Zapevalov. Proceedings of 8th International Workshop, Strong Microwaves and Terahertz Waves: Sources and Applications, Nizhny Novgorod-St.Peterburg, Russia, pp.136-137, (2011). 